\title{
Differences in Fcgamma receptor Ila genotypes and IgG subclass pattern of anti-malarial antibodies between sympatric ethnic groups in Mali
} Elisabeth Israelsson ${ }^{1}$, Manijeh Vafa1, Bakary Maiga ${ }^{1,2}$, Anna Lysén ${ }^{1}$, Nnaemeka C Iriemenam ${ }^{1,3}$, Amagana Dolo², Ogobara K Doumbo², Marita Troye-Blomberg ${ }^{1}$ and Klavs Berzins*1

Address: ${ }^{1}$ Department of Immunology, Wenner-Gren Institute, Stockholm University, Svante Arrheniusväg 16, SE-10691, Stockholm, Sweden, ${ }^{2}$ Malaria Research and Training Center (MRTC), Faculty of Medicine and Pharmacy, University of Bamako, Bamako, Mali and ${ }^{3}$ Department of Medical Microbiology \& Parasitology, College of Medicine, University of Lagos, Nigeria

Email: Elisabeth Israelsson - lisa@imun.su.se; Manijeh Vafa - manijeh@imun.su.se; Bakary Maiga - bmaiga@mrtcbko.org; Anna Lysén - annalysen@yahoo.se; Nnaemeka C Iriemenam - nnaemeka@imun.su.se; Amagana Dolo - adolo@mrtcbko.org; Ogobara K Doumbo - okd@mrtcbko.org; Marita Troye-Blomberg - marita@imun.su.se; Klavs Berzins* - klavs@imun.su.se

* Corresponding author

Published: 15 September 2008

Malaria Journal 2008, 7:175 doi:10.1 186/1475-2875-7-175

This article is available from: http://www.malariajournal.com/content/7/1/175

(C) 2008 Israelsson et al; licensee BioMed Central Ltd.

This is an Open Access article distributed under the terms of the Creative Commons Attribution License (http://creativecommons.org/licenses/by/2.0), which permits unrestricted use, distribution, and reproduction in any medium, provided the original work is properly cited.
Received: 29 April 2008

Accepted: 15 September 2008

\begin{abstract}
Background: The Ig Fc receptor family is an important link between the humoral and cellular immune systems. The association of a dimorphism in amino acid I3I (R/H) of the FcyRlla with malaria severity, the R-allele being associated with a milder disease outcome, led to the investigation of the possible impact of this polymorphism in the interethnic difference in malaria susceptibility seen between the Fulani and Dogon in Mali.
\end{abstract}

Methods: Plasma from individuals from Mali (I64 Fulani and I64 Dogon) were analysed for malaria-reactive and total $\lg G$ subclass antibodies using ELISA, and the same individuals were also genotyped for the FcyRlla RI3IH polymorphism using RFLP-PCR. Statistical analyses of the IgG subclass levels were done by unpaired t-test and ANOVA, and genotype differences were tested by $\chi^{2}$-test.

Results: While the two ethnic groups showed a similar frequency of the $F c \gamma R$ lla $|3| \mathrm{R} / \mathrm{H}$ heterozygote genotype, I3|R/R dominated over the $|3| \mathrm{H} / \mathrm{H}$ genotype in the Dogon whereas the Fulani presented a similar frequency of the two homozygote genotypes. The two alleles were evenly distributed in the Fulani, while the Dogon were clearly biased towards the R-allele. The Fulani showed higher levels of anti-malarial $\operatorname{lgGI},-2$ and -3 antibodies, with a higher proportion of $\lg G 2$, than the Dogon. In the Fulani, $H$-allele carriers had higher anti-malarial $\lg G 2$ levels than $R / R$ homozygotes, while in the Dogon, the R-allele carriers showed the higher lgG2 levels. For antimalarial $\operatorname{lgG} 3$, the R-allele carriers in the Fulani had higher levels than the $\mathrm{H} / \mathrm{H}$ homozygotes.

Conclusion: Taken together, the results showed marked interethnic differences in Fc $\gamma \mathrm{R}$ Ila RI3 IH genotypes. Furthermore, the results indicate that the FcyRlla $\mathrm{R} / 3 \mathrm{IH}$ genotype may influence the IgG subclass responses related to protection against malaria, and that $\lg \mathrm{g} 2$ may be of importance in this context. 


\section{Background}

Malaria remains one of the most prevalent infectious diseases in the world today, with high morbidity and mortality, and no effective control strategies. A rational vaccine design is limited by the lack of knowledge of how the immune system clears the infection. Several studies relate high titers of anti-malarial IgG to protection from severe malaria, and seroepidemiological studies from different endemic areas have demonstrated an association between IgG antibodies of the cytophilic subclasses IgG1 and IgG3 with protection against Plasmodium falciparum malaria $[1,2]$. In other study populations, IgG2 antibodies to certain $P$. falciparum antigens, have been shown to be related to protection $[3,4]$, indicating that the role of the different IgG subclasses in malaria protection still needs to be clarified.

The Fcy receptors on monocytes and other leukocytes are important structures in the immune defence against pathogens. The binding of antibodies to the Fc-receptors provokes important biological functions, e.g. antibody dependent cell-mediated cytotoxicity (ADCC) or inhibition (ADCI) and phagocytosis [5]. In humans, there are three families of Fc-receptors binding IgG, Fc $\gamma$ RI (CD64), -RII (CD32) and -RIII (CD16). FcyRI is a high-affinity receptor that binds monomeric IgG, FcyRII and -RIII are low-affinity receptors, only binding complexed or aggregated IgG. Based on a single nucleotide polymorphism (SNP) in the FcyRIIa gene (G494A) (rs1801274), this receptor has two co-dominantly expressed allotypes, differing at amino acid position $131(\mathrm{R} / \mathrm{H})$. Fc $\mathrm{RIIa}-131 \mathrm{H}$ is the only human FcyR that binds IgG2 efficiently [6]. This polymorphism appears to affect the regulation of the IgG subclass production or turnover in humans [7], which could be a contributing factor to the inconclusive results seen in previous studies on the Fc $\gamma$ RIIa-R131H polymorphism in relation to malaria. Some of the studies are associating the FcyRIIa-131R/R genotype with protection against malaria, and the Fc $\gamma$ RIIa- $131 \mathrm{H} / \mathrm{H}$ genotype with susceptibility to the disease (reviewed by Braga [8]). However, recent publications suggest the FcyRIIa-131H allele to be associated to protection against severe malaria $[9,10]$. This discrepancy is still not understood; it may be caused by different genetic backgrounds or by differences in the pathogen pressure.

Several studies have demonstrated differences in susceptibility to malaria between different ethnic groups. In West Africa, the Fulani were shown to have a lower incidence of malaria than other sympatric groups, despite the same exposure and no differences in socio-cultural circumstances [11]. Studies in Burkina Faso extended those results, demonstrating that the Fulani are less parasitized, less affected by malaria and have higher anti-malarial immune responses than the sympatric Mossi and Rimaibé groups [12]. This is also true for the Malian Fulani and their sympatric neighbours, the Dogon [13]. Previous results have shown that this relative resistance to malaria in the Fulani, as compared to other sympatric tribes, appears to be pathogen related and not due to a general hyper-reactive immune system [14]. Various markers confirm that the Fulani are genetically distinct from other African tribes, and it was thus proposed that established malaria resistance factors would be at a higher frequency in the Fulani, but the reverse was found $[13,15]$.

In an attempt to further define potential genetical and immunological factors contributing to these ethnic differences in malaria susceptibility, the Fc $\gamma$ RIIa genotypes in sympatric individuals from Mali were analysed and related to both the total and the malaria reactive IgG subclass profiles.

\section{Materials and methods Study area}

The study area is located in the Mopti area about $850 \mathrm{~km}$ Northeast of Bamako, the capital of Mali. Four villages (Mantéourou, Naye, Binédama, and Anakédié) were identified for the study. The Mantéourou and Naye are divided into two subdivisions, Mantéourou Peulh/Mantéourou Dogon and Naye Peulh/Naye Dogon-Dinsogou. The two subdivisions are separated by 300-500 meters and inhabited either by Fulani or Dogon. The other two villages, Binédama and Anakédié, are exclusively populated by either Fulani or Dogon, respectively, and are located approximately 1,000 meter apart. Malaria transmission is mesoendemic in the area, with P. falciparum as the main parasite species. The entomological inoculation rate (EIR) is similar in both ethnic groups [13]. In this area the dry season extends from October to May and the rainy season from July to October.

\section{Human samples}

Blood was collected during the rainy season in September 2005 from 328 (164 Fulani and 164 Dogon) asymptomatic, randomly selected donors, aged 1-60 years. For PCR analyses, finger prick blood was collected on filter papers. For plasma samples, either finger prick blood was collected in capillaries or venous blood in vacutainer tubes, both with heparin as anti-coagulant. Spleen enlargement was established based on palpation and graded on the Hackett score $(0-5)$. The proportion of individuals that had enlarged spleens was denoted spleen rate. Informed consent was obtained from all participants or their guardians and it was performed in two steps; first an orally community consent is obtained prior to the study, where the whole community is informed of the aim of the study. Second an individual consent is obtained before blood collection; an alphabetized volunteer sign the form and a non-alphabetized volunteer puts his fin- 
gerprint. The Ethical committee of the Faculty of Medicine and Pharmacy of Mali and the National Ethics Committee in Sweden approved the study.

\section{Plasma preparation}

The capillaries were cut, and blood cells and plasma were separated by centrifugation. The plasmas were stored in $20^{\circ} \mathrm{C}$.

\section{DNA preparation}

DNA was extracted from filter papers using Chelex-100, and then stored at $-20^{\circ} \mathrm{C}$. In brief, discs of the same size were cut out and incubated overnight in $1 \mathrm{ml}$ of $0.5 \%$ saponin in phosphate-buffered saline (PBS) at $4^{\circ} \mathrm{C}$, and were then washed $15-30$ minutes in $1 \mathrm{ml} \mathrm{PBS}$ at $4^{\circ} \mathrm{C}$. The discs were then boiled in $200 \mu \mathrm{l}$ of $5 \%$ Chelex-100 in water for 15 minutes, and the DNA was collected in supernatants after centrifugation at 8,000 $\times \mathrm{g}$ for 3 minutes.

\section{Crude malaria antigen}

Plasmodium falciparum parasites (strain F32) were maintained in continuous cultures as described earlier [16] and kept synchronized by repeated treatment with sorbitol [17]. When the parasitaemia in the cultures was $10 \%$ or more, late stage parasites were isolated on 60\% Percoll, sonicated and used as antigen in the ELISA [18].

\section{Enzyme-linked immunosorbent assay (ELISA)}

EIA/RIA plates (Costar, Corning, NY) were coated overnight at $4^{\circ} \mathrm{C}$ with crude $P$. falciparum antigen in sodium carbonate buffer ( $\mathrm{pH}$ 9.6) at the concentration $10 \mu \mathrm{g} / \mathrm{ml}$. After blocking at $37^{\circ} \mathrm{C}$ with carbonate buffer containing $1 \%$ BSA (w/v) for 2 hours, the plates were washed with saline containing $0.05 \%$ Tween 20 . Serum dilutions (50 $\mu \mathrm{l}, 1: 500$ for IgG1 and IgG3 and 1:50 for IgG2 and IgG4) were added to the plates and incubated $1 \mathrm{~h}$ at $37^{\circ} \mathrm{C}$. To detect IgG2, IgG3 and IgG4, $50 \mu$ l biotin-conjugated mouse anti-human monoclonal antibodies (IgG2: clone G18-21, 1:3000 dilution, PharMingen, San Diego, CA. IgG3: clone HP6047, 1:1000 dilution, Caltag Laboratories, Burlingame, CA. IgG4: clone HP6025, 1:2000 dilution, Sigma, St. Louis, MO) and alkaline phosphatase conjugated streptavidine (Mabtech $\mathrm{AB}$, Sweden) were used. Detection of IgG1 was done with a monoclonal mouse anti-human IgG1 antibody (50 $\mu$ l of 1:1000 dilution, clone NL16-purified, SkyBio Limited, Bedfordshire, U.K) and alkaline phosphatase conjugated goat antimouse Ig (Dako Denmark A/S, Glostrup, Denmark). The assay was developed with p-nitrophenyl phosphate disodium salt (Sigma, St. Louis, MO) as substrate and the optical densities were read at $405 \mathrm{~nm}$ in ELISA plate reader (VmaxTM Kinetic Microplate Reader, Menlo Park, CA). The concentrations of anti-malarial antibodies, expressed as ELISA-units (a $\mu \mathrm{g} / \mathrm{ml}$ equivalent), were calculated from standard curves obtained in a sandwich ELISA with six dilutions of myeloma proteins of the IgG1-4 isotypes (Serotec, Oxford, UK). No cross reactivity between the different subclass reagents were detected in this system.

The total concentrations of IgG subclass $1-4$ were determined with PeliClass human IgG subclass kit (Sanquin Reagents, Amsterdam, The Netherlands). In short, precoated micro titre plates where incubated with diluted sera (1:30 000 for IgG2, IgG3 and IgG4 and 1:240 000 for IgG1) at $37^{\circ} \mathrm{C}$ for $1 \mathrm{~h}$. For detection, an HRP-conjugated anti-human IgG antibody was used and the assay was developed with ABTS-substrate and read at $405 \mathrm{~nm}$ in ELISA plate reader (VmaxTM Kinetic Microplate Reader, Menlo Park, CA).

\section{RFLP analysis of the Fc $/$ RIla polymorphism}

The R131H FcyRIIa polymorphism (rs1801274) was investigated using restriction fragment length polymorphism (RFLP) analysis as described by Jiang et al [19]. The PCR amplification was performed in $10 \mu \mathrm{l}$ reactions using $2.5 \mu \mathrm{l}$ of genomic DNA, $5 \mu$ l of $2 \times$ ready-to-use PCR Master Mix (ABgene, Surrey, UK.) and $0.25 \mu \mathrm{l}$ of each primer (Forward: 5'-GGAAAATCCCAGAAATTCTCGC-3' and Reverse: 5'-CAACAGCCTGACTACCTATTACGCGGG-3', (MWG-Biotech AG, Ebersberg, Germany)). The PCR was carried out in an Eppendorf Mastercycler ${ }^{\circledR}$ (Eppendorf AG, Hamburg, Germany) using a $10 \mathrm{~min}$ denaturation at $94^{\circ} \mathrm{C}$ followed by 35 cycles with $94^{\circ} \mathrm{C}$ for $30 \mathrm{sec}, 56^{\circ} \mathrm{C}$ for $30 \mathrm{sec}$ and $72^{\circ} \mathrm{C}$ for $45 \mathrm{sec}$. The final extension was at $72^{\circ} \mathrm{C}$ for $5 \mathrm{~min}$. Five $\mu \mathrm{l}$ of the PCR product were used for the enzymatic digestion with $2.5 \mathrm{U}$ Bsh12361 (Fermentas $\mathrm{GMBH}$, St Leon Rt, Germany) at $37^{\circ} \mathrm{C}$ over night. The resulting fragments (H/H: $343 \mathrm{bp}, 23 \mathrm{bp}, \mathrm{R} / \mathrm{R}: 322 \mathrm{bp}, 44$ bp, H/R: 343 bp, 322 bp, 44 bp, 23 bp) were analyzed on ethidium bromide stained $2.5 \%$ agarose gels.

\section{Parasite detection by PCR}

In order to detect an ongoing $P$. falciparum infection and to determine the number of merozoite surface protein (msp) 2 (FC27 and 3D7) clones per infection, a nested PCR was performed. Amplifications were done in a $10 \mu \mathrm{l}$ reaction using $2.5 \mu \mathrm{l}$ of DNA, iProof ${ }^{\mathrm{TM}}$ High-Fidelity Master Mix (BIO-RAD Laboratories, Hercules, CA) and 500 $\mathrm{nM}$ of primer pairs corresponding to the outer conserved region of the polymorphic repetitive block 3 of $m s p 2$. DNA was denatured at $98^{\circ} \mathrm{C}$ for $1 \mathrm{~min}$; then PCR was performed for 30 cycles of $98^{\circ} \mathrm{C}$ for $10 \mathrm{sec}, 61^{\circ} \mathrm{C}$ for $20 \mathrm{sec}$ and $72^{\circ} \mathrm{C}$ for $30 \mathrm{sec}$, with a final $5 \mathrm{~min}$ extension. One $\mu \mathrm{l}$ of the PCR product was re-amplified with primers specific for FC27 and IC/3D7 allelic types of $m s p 2$, using the following program: $30 \mathrm{sec}$ at $98^{\circ} \mathrm{C} ; 25$ cycles of $98^{\circ} \mathrm{C}$ for 10 sec, $61^{\circ} \mathrm{C}$ for $20 \mathrm{sec}$ and $72^{\circ} \mathrm{C}$ for $10 \mathrm{sec}$ and a final extension for $5 \mathrm{~min}$. The primer sequences were presented elsewhere [20]. The number of products, corresponding to the number of infecting FC27 and IC/3D7 clones, was 
counted after visualization on ethidium bromide (EtBr) stained 2.5 and $1.5 \%$ agarose gel, respectively.

\section{Hb AS genotyping}

To detect HbAS carriers a PCR procedure was used. In short, the PCR amplification was performed in $10 \mu \mathrm{l}$ reactions using $2 \mu$ l of genomic DNA, $5 \mu$ l of $2 \times$ ready-to-use PCR Master Mix (ABgene, Surrey, UK.) and $0.25 \mu$ l of each primer (Forward: 5'-ACACAACTGTGTTCACTAGC-3' and Reverse: 5'-CAACTTCATCCACGTTCACC-3', (MWG-Biotech AG, Ebersberg, Germany)). The PCR was carried out in an Eppendorf Mastercycler ${ }^{\circledR}$ (Eppendorf AG, Hamburg, Germany) using a 5 min denaturation at $95^{\circ} \mathrm{C}$ followed by 35 cycles with $95^{\circ} \mathrm{C}$ for $30 \mathrm{sec}, 56^{\circ} \mathrm{C}$ for $30 \mathrm{sec}$ and $72^{\circ} \mathrm{C}$ for $30 \mathrm{sec}$. The final extension was at $72^{\circ} \mathrm{C}$ for 5 min. The entire PCR product were used for the enzymatic digestion with $4 \mathrm{U} \mathrm{DdeI} \mathrm{(Invitrogen)} \mathrm{at} 37^{\circ} \mathrm{C}$ for $2 \mathrm{~h}$. The resulting fragments were analyzed on ethidium bromide stained $2.5 \%$ agarose gels.

\section{Statistical analysis}

All the statistical analyses were performed in StatView version 5.0.1 if not stated otherwise. Differences in malariometric indexes between the two ethnic groups were tested with Mann-Whitney U-test. The observed genotype frequencies of the Fc $\gamma$ RIIa R131H polymorphism in the two ethnic groups were tested for differences with $\chi^{2}$-test. Multiple regression analyses, with IgG subclasses as dependent variables and age, ethnicity, gender, parasite density and FcrRIIa R131H genotypes as independent variables, were performed to assess the influence on these variables on IgG subclass levels. Association analyses were performed in Unphased version 3.0.7.

As the antibody data did not show normal distribution, they were log-transformed, after which they all were nor- mally distributed. Comparisons between the two ethnic groups were done using unpaired t-test. For analyses of genotype and IgG subclass levels, ANOVA was used. To determine differences between the populations, the Fisher's PLSD was used.

To test for potential ethnic differences, as well as for genotype-based differences in spleen rate, $\chi^{2}$-test was used. Ethnic and genotype-based differences in parasite density, numbers of parasite clones and haemoglobin levels were analysed by Mann-Whitney U-test or Kruskal-Wallis test.

A p-value of 0.05 or less was considered to be significant, and p-values between $0.05-0.1$ were considered to be marginally significant. No correction for the number of tests was done, so there is a risk of presenting some overestimated significances.

\section{Results \\ Study population}

There were no differences in age and gender between the two study populations (Table 1). The parasite prevalence differed between the two ethnic groups, 58\% being infected among the Dogon, compared to $43 \%$ among the Fulani ( $\mathrm{p}=0.008$ ). Also, the number of circulating parasite clones differed between the groups, the Dogon having more parasite clones than the Fulani $(5.6 \pm 2.9$ and $4.5 \pm$ 2.7 , respectively, $\mathrm{p}=0.02$ ) (Table 1 ). With regard to spleen rate, the Fulani had an enlarged spleen more frequently as compared to the Dogon (37\% and $11 \%$, respectively; $\mathrm{p}<0.0001)$ (Table 1$)$. The haemoglobin levels were found to be significantly higher in the Dogon group than in the Fulani $(13.1 \pm 2.4$ and $10.6 \pm 2.5$, respectively, $\mathrm{p}<0.0001$ ) (Table 1 ). The frequencies of $\mathrm{Hb}$ AS were found to be similar in the two ethnic groups (7.2\% in Dogon and 7.9\% in Fulani) (Table 1).

Table I: Malariometric indexes in the participating Fulani and Dogon communities in Mali

\begin{tabular}{|c|c|c|c|}
\hline & Dogon & Fulani & $P$ value $^{a}$ \\
\hline Age-range (years) & $1-58$ & $1-60$ & \\
\hline Age-median (years) & 16 & 14.5 & \\
\hline Gender distribution (\% women) & 48 & 49 & \\
\hline Spleen rate ${ }^{\mathrm{b}}(\%)$ & II & 37 & $<0.0001$ \\
\hline Parasite prevalence ${ }^{c}(\%)$ & 58 & 43 & 0.008 \\
\hline Number of clones ${ }^{d} \pm S D$ & $5.63 \pm 2.85$ & $4.52 \pm 2.7$ & 0.02 \\
\hline Parasite density \pm SD & $662 \pm 3206$ & $716 \pm 2844$ & ns \\
\hline Haemoglobin levels (mean \pm SD) & $13.1 \pm 2.4$ & $10.6 \pm 2.5$ & $<0.0001$ \\
\hline HbAS prevalence $(\%)$ & 7.2 & 7.9 & ns \\
\hline Number of subjects & 164 & 164 & \\
\hline
\end{tabular}

a Differences between the two ethnic groups tested by Mann-Whitney $U$ test

b Percentage of individuals with enlarged spleen

c Proportion of infected individuals, measured by PCR

d Mean number of clones identified as msp2 alleles, excluding PCR negatives

e $P$. falciparum density (parasites/ $\mu \mathrm{l})$-mean. 


\section{Fc/RIIa $R$ I 3 IH genotyping}

All individuals of the two study groups were genotyped for the G494A single nucleotide polymorphism (R131H) in the FcrRIIa gene (rs1801274). Both allele and genotype frequencies were found to be in Hardy-Weinberg equilibrium. While both ethnic groups showed a similar frequency of heterozygotes $(131 \mathrm{H} / \mathrm{R})$, there was a statistically significant difference with regard to the frequency of homozygotes (Table 2). The 131R/R genotype was dominating among the Dogon, while the homozygote genotypes were evenly distributed in the Fulani ( $\mathrm{p}=$ $0.0008)$. This genetic difference between the two ethnic groups was even more pronounced when comparing the allele frequencies, the $131 \mathrm{H}$ and $131 \mathrm{R}$ alleles being presented in equal frequencies in the Fulani and the $131 \mathrm{R}$ allele dominating in the Dogon ( $\mathrm{p}<0.0001)$ (Table 2). Moreover, weak associations were found between the $\mathrm{H}$ allele and the Fulani ethnic group $(\mathrm{OR}=0.73, \mathrm{p}=0.05)$ and the R-allele and the Dogon ethnic group $(\mathrm{OR}=1.37$, $\mathrm{p}=0.05)$.

\section{IgG subclass distribution}

Possible differences in relation to ethnicity or Fc $\gamma$ RIIa genotypes and patterns of total- or anti-malarial IgG subclasses were analysed. All IgG subclasses, except for IgG4, increased in concentration with age for both ethnic groups. For total IgG subclass levels, the Dogon showed slightly higher IgG4 concentrations than the Fulani ( $\mathrm{p}=$ 0.03 ), while none of the other subclasses showed any difference between the two ethnic groups (Figure 1A).

For the anti-malarial IgG antibody subclasses, the Fulani showed significantly higher levels of $\operatorname{IgG} 1(\mathrm{p}=0.0003)$, IgG2 and IgG3 ( $\mathrm{p}<0.0001$, respectively). For anti-malarial IgG4, both ethnic groups showed very low levels and no difference between the ethnic groups was seen ( $\mathrm{p}=$ 0.2 ). (Figure $1 \mathrm{~B}$ ). The most dominant subclass among the anti-malarial antibodies was IgG1, followed by IgG3, IgG2 and IgG4 in both ethnic groups. However, some Fulani individuals showed a stronger IgG2 than IgG3 response, hence, for those individuals the pattern was IgG1 followed by IgG2, IgG3 and IgG4 (Figure 1B.). Comparison between the two ethnic groups, of what proportion of the total IgG subclasses were represented by antimalarial antibodies, showed that the Fulani group had a significantly higher percentage of anti-malarial antibodies than the Dogon for all IgG subclasses, except for IgG4 (Table 3).

The patterns of the different IgG subclasses among the anti-malarial antibodies and total IgGs were compared between the two ethnic groups, analysing the ratios of IgG1/IgG2, IgG1/IgG3 and IgG2/IgG3 (Table 4). IgG4 was excluded from this analysis, since the levels of anti-malarial IgG4 were consistently low in both groups. While the ratios for anti-malarial IgG1/IgG3 did not differ between the two groups $(\mathrm{p}=0.3)$, the ratios including IgG2 indicated that the Fulani have a more IgG2 directed response than Dogon (IgG1:IgG2 and IgG2:IgG3, p < 0.0001, respectively). This was not reflected in the ratios regarding total IgG subclass levels, where no differences between the two ethnic groups were seen.

\section{Fc/RIla $R / 3$ I $H$ and distribution of $P$. falciparum-reactive IgG subclasses}

In order to see if the Fc $\gamma$ RIIa R131H genotype could have an effect on the $P$. falciparum-reactive IgG subclass levels, multiple regression analyses with the different IgG subclass antibody levels as dependent variables were performed. When adjusted for age, gender, ethnicity and parasite density, the Fc $\gamma$ RIIa R131H genotype showed a weak but significant predictive effect on $P$. falciparum-reactive IgG3 levels (adjusted $\mathrm{R}^{2}=0.324$ and $\mathrm{p}=0.027$ ) with higher levels in individuals homozygous for the R-allele, and a non-significant effect on total IgG1 levels (adjusted $\mathrm{R}^{2}=0.117$ and $\mathrm{p}=0.09$ ), with higher IgG1 levels in $\mathrm{HH}$ carriers. When separating the two ethnic groups in the analyses, the Fc $\gamma$ RIIa R131H genotype showed a tendency for a predictive effect on $P$. falciparum-reactive IgG2 levels in both Fulani and Dogon (adjusted $\mathrm{R}^{2}=0.266$ and $\mathrm{p}=$ 0.08 and adjusted $\mathrm{R}^{2}=0.350$ and $\mathrm{p}=0.06$, respectively). Higher antibody levels where found in $\mathrm{HH}$ carriers in the Fulani, while RR carriers had higher levels in the Dogon,

The total IgG1 levels in the Fulani were significantly but still weakly predicted by the Fc $\mathrm{RIIa}$ R131H genotype $(\mathrm{p}=$ $0.04)$.

In order to further decipher the possible influence of the FcyRIIa R131H genotypes on IgG subclass levels, comparisons of the levels of the different IgG subclasses among the $P$. falciparum-reactive antibodies between the different Fc $\gamma$ RIIa R131H genotypes were performed. Overall geno-

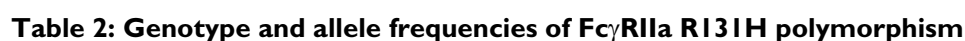

\begin{tabular}{lccccccc}
\hline Tribe & $\mathrm{R} / \mathrm{R}$ & $\mathrm{H} / \mathrm{R}$ & $\mathrm{H} / \mathrm{H}$ & P-value $^{\mathbf{a}}$ & $\mathrm{R}$-allele & H-allele $^{\text {P-value }^{\mathbf{a}}}$ \\
\hline Dogon & $65(41 \%)$ & $71(44 \%)$ & $24(15 \%)$ & $\mathbf{0 . 0 0 0 8}$ & $20 \mathrm{I}(63 \%)$ & $119(37 \%)$ & $<\mathbf{0 . 0 0 0 1}$ \\
Fulani & $39(24 \%)$ & $78(48 \%)$ & $47(29 \%)$ & & $156(48 \%)$ & $172(52 \%)$ & \\
\hline
\end{tabular}

a Statistical analysis of differences in frequencies between the two ethnic groups tested with $\chi^{2}$-test. 

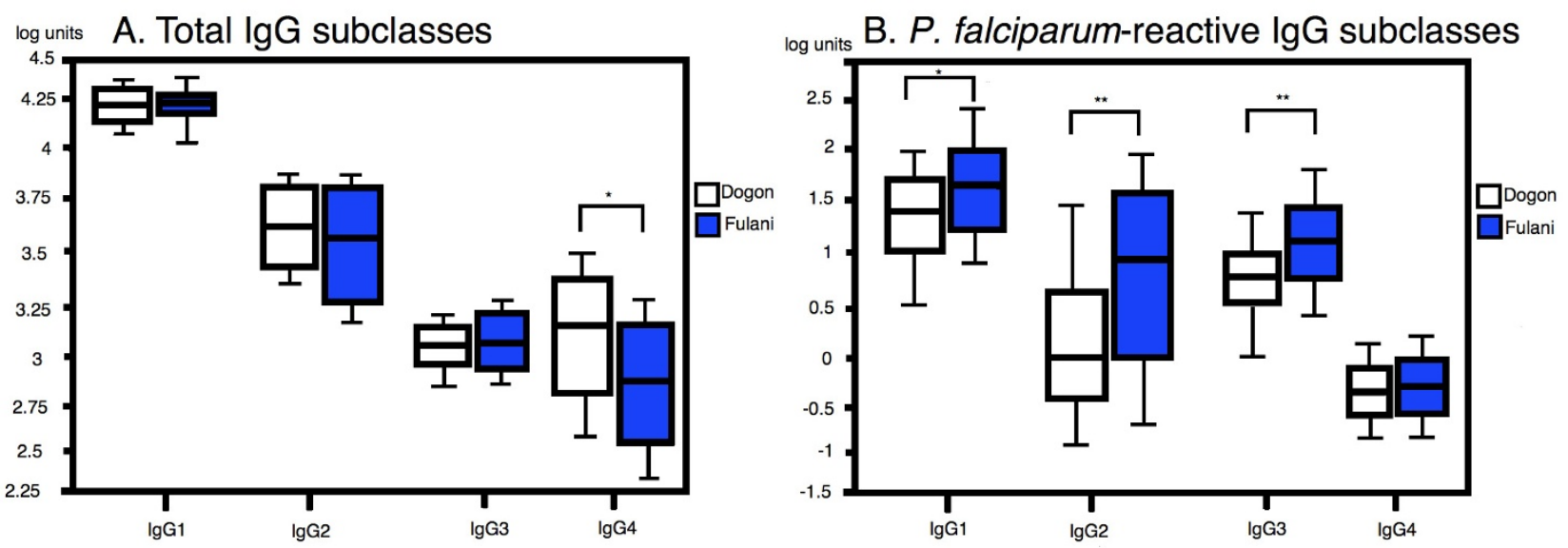

Figure I

The distribution of total IgG subclasses (A), and $P$. falciparum-reactive IgG subclasses (B), as assessed by

ELISA. The results are expressed in ELISA units and the values are represented as the log 10 values of the concentration of each IgG subclass. The boxes represent the values between the $25 \%$ to the $75 \%$ quartile and the line indicates the median. The whiskers indicate the $10 \%$ and the $90 \%$ quartile. Statistical analysis done by unpaired t-test. $* \mathrm{P}<0.05, * * \mathrm{P}<0.000 \mathrm{I}$.

type differences regarding both IgG2 and IgG3 levels were seen for both ethnic groups, as well as a difference in IgG4 levels in the Fulani ethnic group (Table 5). For the Dogon, the $\mathrm{H} / \mathrm{H}$ individuals showed a lower anti-malarial IgG2 level than both $H / R$ and $R / R$ carriers $(p=0.02)$, while the $\mathrm{H} / \mathrm{R}$ individuals had lower levels of $P$. falciparum-reactive IgG3, than the $\mathrm{R} / \mathrm{R}$ individuals ( $\mathrm{p}=0.03$ ). For the Fulani, the $\mathrm{R} / \mathrm{R}$ individuals showed lower IgG2 concentrations than the $H / R$ subjects $(p=0.05)$, but there was also a tendency for $\mathrm{H} / \mathrm{H}$ individuals to present higher IgG2 levels than R/R genotype carriers. The concentrations of IgG3 were lower in the $\mathrm{H} / \mathrm{H}$ individuals compared to the $\mathrm{H} / \mathrm{R}$ heterozygotes $(\mathrm{p}=0.01)$, but there was also a tendency for lower levels as compared to R/R subjects. For anti-malarial IgG4 concentrations, the $\mathrm{H} / \mathrm{H}$ homozygotes had lower levels than $H / R$ individuals $(\mathrm{p}=0.04)$.

Table 3: Geometric mean percentage of $P$. falciparum reactive IgG subclasses among the total IgG subclass concentration.

\begin{tabular}{|c|c|c|c|c|}
\hline & \multicolumn{4}{|c|}{ Specific lgG subclasses/total lgG subclasses (\%) } \\
\hline & $\lg G \mid$ & $\lg G 2$ & $\lg \mathrm{g} 3$ & $\lg G 4$ \\
\hline Dogon & $2.4 \pm 1.2$ & $1.8 \pm 1.5$ & $1.8 \pm 1.3$ & $0.7 \pm 1.5$ \\
\hline Fulani & $3.2 \pm 1.2$ & $2.6 \pm 1.4$ & $2.4 \pm 1.7$ & $0.8 \pm 1.4$ \\
\hline p-value ${ }^{a}$ & $<0.0001$ & 0.0005 & $<0.0001$ & 0.11 \\
\hline
\end{tabular}

Data are presented as geometric mean percentages (the mean percentages of the logged values) \pm SD.

a Statistical analysis of differences between the two ethnic groups for each IgG subclass tested with t-test.
Analysis of the R-allele carriers in comparison with the $\mathrm{H} /$ $\mathrm{H}$ homozygotes revealed that there was only a difference regarding IgG3 in the Fulani (Table 6), with R-allele carriers having higher mean levels of anti-malarial IgG3 than $\mathrm{H} / \mathrm{H}$ homozygotes $(\mathrm{p}=0.004)$. The Dogon, on the other hand, only showed a statistically significant difference regarding IgG2, with R-allele carriers having higher mean levels of anti-malarial IgG2 than $\mathrm{H} / \mathrm{H}$ homozygotes $(\mathrm{p}=$ 0.007). A comparison between $\mathrm{H}$-allele carriers and $\mathrm{R} / \mathrm{R}$ homozygotes (Table 6) showed a significant difference in malaria specific IgG3 levels for Dogon $(p=0.009)$, with $\mathrm{H}$-allele carriers having lower levels than $\mathrm{R} / \mathrm{R}$ homozygotes. The Fulani showed a significant difference regarding IgG2, where the H-allele carriers had higher levels than $\mathrm{R} / \mathrm{R}$ homozygotes $(\mathrm{p}=0.02)$.

\section{Fc $R$ RIIa RI 3 IH and malariometric data}

In order to see if the FcrRIIa R131H genotypes affected haemoglobin levels, parasite density, number of circulating parasite clones, frequency of $\mathrm{Hb}$ AS and spleen rate, analyses of these parameters within each genotype were performed. No differences were found for parasite density, haemoglobin levels or spleen rate. The number of circulating parasite clones differed in the Fulani group, where individuals with the RR genotype had higher numbers of clones than $\mathrm{HR}$ and $\mathrm{HH}$ genotype individuals (mean \pm SD: $3.3 \pm 3.5,1.3 \pm 2.5$ and $1.9 \pm 2.6$, respectively, $\mathrm{p}=0.006$ ) (Table 6). Also, the frequency of Hb AS carriers differed between the genotypes in the Fulani group, again RR individuals having a higher $\mathrm{Hb}$ AS frequency than HR and HH individuals ( $p=0.01$, Table 6). When comparing the parasite prevalence, it was found 
Table 4: Ratio between IgG subclasses, both $P$. falciparum reactive and total.

\begin{tabular}{|c|c|c|c|c|c|c|}
\hline & \multicolumn{3}{|c|}{ P. falciparum specific lgG subclasses } & \multicolumn{3}{|c|}{ Total IgG subclasses } \\
\hline & $\lg \mid: \lg G 2$ & $\lg G \mid: \lg G 3$ & $\lg G 2: \lg G 3$ & $\lg G \mid: \lg G 2$ & $\lg G \mid: \lg G 3$ & $\lg G 2: \lg G 3$ \\
\hline Dogon & $4.3: 1$ & $4.9: 1$ & $1.1: 1$ & $4.3: 1$ & $13.6: 1$ & $3.1: 1$ \\
\hline Fulani & $2.5: 1$ & $4.6: 1$ & $1.8: 1$ & $3.6: 1$ & $13: 1$ & $3.6: 1$ \\
\hline p-value ${ }^{a}$ & $<0.0001$ & 0.28 & $<0.0001$ & 0.2 & 0.26 & 0.48 \\
\hline
\end{tabular}

Data are presented as the mean ratio.

a Statistical analysis of differences in ratios between the two ethnic groups tested with t-test.

that the Fulani HR carriers had a higher frequency of parasite positivity than the other genotypes (Table 6). Furthermore, when comparing only the parasite positive, a difference in distribution pattern was found between the ethnic groups. While the Fulani showed an even distribution of parasite positive individuals between the genotypes, the Dogon had a lower frequency of parasite positive individuals with the $\mathrm{HH}$ genotype than in $\mathrm{HR}$ and RR (Fulani: HH: 32\%, HR: 36\%, RR: 32\%, Dogon: HH: $17 \%$, HR: $43 \%$, RR: $40 \%$. p $=0.066$ ), but this difference in patterns did not reach statistical significance.

\section{Discussion}

This study shows that two sympatric ethnic groups in Mali, the Fulani and the Dogon, exhibit differential frequencies in the expression of Fc $\gamma$ RIIa R131H genotypes and allotypes. It furthermore, confirms and extends the previous findings regarding differences in anti-malarial responses between sympatric ethnic groups living in West Africa $[12,13]$. The Fulani were less parasitized, had fewer parasite clones and had higher anti-malarial IgG subclass levels than the sympatric ethnic group, the Dogon. Fulani also showed a higher spleen rate as compared to Dogon. Interestingly, the Fulani showed significantly lower haemoglobin levels as compared to the Dogon, which was recently confirmed in both a longitudinal study and two cross sectional studies in the same study area (Dolo et al, personal communication).

The FcyRIIa R131H genotype results of this study contradict those from previous reports, where the R/R genotype has been associated with protection (reviewed by Braga [8]). Here it was revealed that the $\mathrm{H} / \mathrm{H}$ genotype is more common in the Fulani, who are considered to be less susceptible to malaria, and this was recently confirmed by a study in Sudan [21], where the $\mathrm{H}$ allele was more common in the Fulani group than in the sympatric Masaleit group. In line with these findings, others have recently reported that the $\mathrm{H} / \mathrm{H}$ genotype is related to protection $[9,10,22]$, suggesting that the $\mathrm{H} / \mathrm{H}$ genotype might contribute to the relative protection from malaria in the Fulani. The influence of the FcyRIIa R131H polymor-

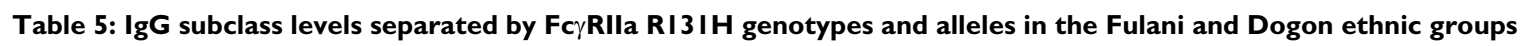

\begin{tabular}{|c|c|c|c|c|c|c|c|c|c|c|c|c|}
\hline & \multicolumn{6}{|c|}{ Dogon } & \multicolumn{6}{|c|}{ Fulani } \\
\hline & no. & age & $\lg G \mid$ & $\lg G 2$ & $\lg G 3$ & $\lg G 4$ & no. & age & $\lg G \mid$ & $\lg G 2$ & $\lg G 3$ & $\lg G 4$ \\
\hline $\mathrm{H} / \mathrm{H}$ & 24 & 15 & $15 \pm 2.9$ & $0.4 \pm 5.6$ & $4.5 \pm 3.5$ & $0.54 \pm 2.0$ & 39 & 15 & $34 \pm 4.4$ & $5.9 \pm 11$ & $6.3 \pm 2.5$ & $0.29 \pm 7.8$ \\
\hline$H / R$ & 69 & 16 & $17 \pm 3.9$ & $1.2 \pm 6.7$ & $3.8 \pm 2.6$ & $2.3 \pm 2.3$ & 68 & 23 & $38 \pm 3.7$ & $7.5 \pm 9.1$ & $12 \pm 2.8$ & $1.8 \pm 2.6$ \\
\hline$R / R$ & 64 & 20 & $24 \pm 3.5$ & $1.5 \pm 8.1$ & $6.2 \pm 2.9$ & $0.41 \pm 2.9$ & 36 & 21 & $24 \pm 3.4$ & $2.4 \pm 9.8$ & $9.5 \pm 2.9$ & $0.42 \pm 2.3$ \\
\hline p-value ${ }^{a}$ & & 0.07 & 0.2 & 0.02 & 0.03 & 0.5 & & 0.07 & 0.2 & 0.05 & 0.01 & 0.04 \\
\hline R-allele carriers & 133 & 18 & $20 \pm 3.7$ & $1.3 \pm 7.3$ & $4.8 \pm 2.8$ & $0.43 \pm 2.5$ & 93 & 22 & $33 \pm 3.6$ & $5.0 \pm 10$ & $11 \pm 2.8$ & $0.5 \pm 2.5$ \\
\hline p-value ${ }^{b}$ & & 0.3 & 0.4 & 0.007 & 0.8 & 0.2 & & 0.03 & 0.08 & 0.1 & 0.009 & 0.4 \\
\hline $\mathrm{H}$-allele carriers & 104 & 22 & $17 \pm 3.6$ & $0.89 \pm 6.7$ & $3.9 \pm 2.8$ & $0.46 \pm 2.3$ & 107 & 20 & $37 \pm 3.9$ & $6.8 \pm 9.5$ & $9.4 \pm 2.8$ & $0.44 \pm 4.4$ \\
\hline p-value ${ }^{c}$ & & 0.02 & 0.9 & 0.7 & 0.004 & 0.02 & & 0.9 & 0.09 & 0.02 & 0.9 & 0.8 \\
\hline
\end{tabular}

The results are expressed in ELISA units and presented as geometric means \pm SD.

a Statistical analysis of differences in $\lg G$ subclass levels between the different genotypes tested with ANOVA

b Statistical analysis of differences in IgG subclass levels between the R-allele carriers and HH homozygotes Mann-Whitney.

c Statistical analysis of differences in IgG subclass levels between the $\mathrm{H}$-allele carriers and RR homozygotes by Mann-Whitney. 
Table 6: Malariometric indexes separated by FçRIIa RI 3 I H genotypes in the Fulani and Dogon ethnic groups.

\begin{tabular}{|c|c|c|c|c|c|c|c|c|}
\hline & \multicolumn{4}{|c|}{ Dogon } & \multicolumn{4}{|c|}{ Fulani } \\
\hline & $\mathrm{HH}$ & $\mathrm{HR}$ & $\mathrm{RR}$ & p-value ${ }^{a}$ & $\mathrm{HH}$ & $\mathrm{HR}$ & $\mathrm{RR}$ & p-value a \\
\hline Age (mean $\pm s d)$ & $15 \pm 12$ & $16 \pm 13$ & $20 \pm 13$ & & $15 \pm 13$ & $23 \pm 18$ & $20 \pm 17$ & \\
\hline Spleen rate ${ }^{\mathrm{b}}(\%)$ & 8 & 13 & II & 0.8 & 38 & 36 & 36 & 0.9 \\
\hline $\mathrm{Hb}($ mean $\pm \mathrm{sd})$ & $13 \pm 2$ & $12.6 \pm 2.4$ & $13.3 \pm 2.6$ & 0.4 & $1 \mid \pm 2$ & $10.6 \pm 2.7$ & $10.8 \pm 2.3$ & 0.9 \\
\hline Parasite prevalence ${ }^{c}(\%)$ & 67 & 58 & 60 & 0.7 & 49 & 33 & 59 & 0.02 \\
\hline Parasite density ${ }^{d}($ mean $\pm s d)$ & $907 \pm 4138$ & $546 \pm 1803$ & $243 \pm 843$ & 0.5 & $330 \pm 1138$ & $530 \pm 2155$ & $1533 \pm 4734$ & 0.2 \\
\hline Clones $^{e}($ mean $\pm s d)$ & $4.0 \pm 3.7$ & $2.9 \pm 3.3$ & $3.6 \pm 3.7$ & 0.4 & $1.9 \pm 2.6$ & $1.3 \pm 2.5$ & $3.3 \pm 3.5$ & 0.006 \\
\hline $\operatorname{HbAS} \mathrm{f}(\%)$ & 0 & 10 & 6 & 0.2 & 6 & 3 & 18 & 0.01 \\
\hline
\end{tabular}

a Differences between the three different genotypes.

b Percentage of individuals with enlarged spleen

c Proportion of infected individuals, measured by PCR

d $P$. falciparum density (parasites/ $\mu \mathrm{l}$ )-mean

e Mean number of clones identified as msp2 alleles, excluding PCR negatives

f Frequency of HbAS carriers detected by PCR.

phism on the relative susceptibility to malaria, could in part be due to the association of this polymorphism with a differential IgG subclass production or turnover [7]. In line with this, the present study shows an association between differential levels of IgG1 and IgG3 antibodies and FcyRIIa R131H genotypes. The previous suggestion, that the presence of the R-allele is an important factor in protection from severe disease [23] is compatible with the finding in this study that the Fulani had higher levels of anti-malarial IgG3 among the R-allele carriers than among the $\mathrm{H} / \mathrm{H}$ individuals. Also the Dogon group showed higher IgG3 antibody levels among R/R homozygotes than the $\mathrm{H}$-allele carriers. In individuals from the Dogon ethnic group, the R-allele also seems to be related to higher IgG2 levels, while in Fulani, the H-allele carriers have higher IgG2 levels. Why the two ethnic groups have different distribution of the IgG2 subclass is not known. However, it may be speculated that since the Fc $\gamma$ RIIa 131R receptor is being less effective in binding IgG2, more IgG2 will be present free in the circulation of individuals with the R-allele than those with the H-allele. This could explain the higher IgG2 levels found in Dogon individuals carrying the R-allele, but not the higher IgG2 levels in the Fulani individuals carrying the $\mathrm{H}$-allele. Interestingly, the Fulani show a FcyRIIa genotype frequency similar to what has previously been reported for Caucasians [24,25], while the Dogon have the same $\mathrm{H} / \mathrm{H}$ frequency as AfricanAmericans [25], but differs regarding R/R and R/H genotype frequency. Since the Fulani have been shown to be closer to Caucasians than Africans for some genetic markers [26], the difference seen between the two ethnic groups regarding FcyRIIa appears therefore not to have been driven by malaria pressure, but rather be a reflection of their different genetic background.

The impact of the FcyRIIa R131H polymorphism on the clinical outcome of malaria has been shown in several studies $[3,4,9,10,22,23,27-29]$. In this study, however, the analyses of a possible effect of the polymorphism on some malariometric factors (age, spleen rate, haemoglobin levels, parasite density, number of clones and carriage of $\mathrm{Hb} \mathrm{AS}$ ) showed that only the frequency of $\mathrm{Hb} \mathrm{AS}$ and the number of circulating clones differed, with $\mathrm{H}$ allele carriers having a lower Hb AS frequency and fewer clones than R/R homozygotes, but only in the Fulani group (Table 6). It has been indicated that the number of clones is related to protection against severe malaria [30], and together with the present results, it appears that the $\mathrm{H}$-allele might be a prognostic factor in this context. It is important to notice that this parameter fluctuates considerably in individuals [31] and that it is difficult to conclude anything based on only one measurement. The unequal balance in the distribution of parasite positive individuals between the genotypes found in the Dogon, where the HH homozygotes had fewer positive individuals than the HR and RR genotype groups, may suggest that the HH genotype could be more protective due to the pattern of fewer parasite positive individuals in this group.

No differences between the two ethnic groups were shown when comparing total IgG subclasses, except for IgG4, were the Dogon showed slightly higher concentrations than the Fulani. This confirms the previous suggestion, that the relative resistance seen in the Fulani as compared to other sympatric ethnic groups appears to be pathogen related, and not a result of a generally more activated immune system in the Fulani [14].

Regarding anti-malarial IgG subclasses, the Fulani had higher levels of all subclasses, except for IgG4, which was very low in both ethnic groups. When calculating the percentage of anti-malarial IgG subclass antibodies within the total IgG concentrations, the Fulani showed a higher percentage of all IgG subclasses of anti-malarial antibod- 
ies, except for IgG4, where there were no differences between the two ethnic groups. For the ratios between IgG1:IgG2, IgG1:IgG3 and IgG2:IgG3, the Fulani had higher IgG1, IgG2 and IgG3 levels, while the Dogon had predominant IgG1 and IgG3 responses. Previous studies suggest that IgG1 and IgG3 are the most important IgG subclasses in the protection against malaria [1]. IgG1 and IgG3 are known to opsonate infected red blood cells, while IgG2 and IgG4 have been shown to inhibit this opsonization. [32]. However, other reports suggest a protective role of anti-malarial IgG2 [32], and high IgG2 and low IgG4 levels of anti-malarial antibodies have been associated with resistance to $P$. falciparum malaria [3]. The data reported here showed that the Fulani have higher anti-malarial IgG2 levels compared to the Dogon, while IgG4 were similarly low in the two ethnic groups. This suggests that the association of high IgG2 and low IgG4 levels reported by Aucan et al [3] could be a contributing factor for the relative resistance to malaria seen in the Fulani. However, even though the results presented here do not contradict this suggestion, the IgG4 concentrations were overall very low in this study and were therefore excluded from the analyses. Thus, the role of IgG4 in the ethnic differences in malaria susceptibility seen between the Fulani and the Dogon of Mali remains to be investigated.

Carriage of haemoglobin AS has been reported to influence the anti-malarial IgG2 concentrations in Gabonese children, which was independent of the FcrRIIa R131H genotype [4]. Preliminary observations did not detect any influence of carriage of haemoglobin AS on anti-malarial IgG2 levels in this study. No differences in frequency of AS carriers between the ethnic groups were seen $(7.2 \%$ in Dogon and $7.9 \%$ in Fulani), and there was no difference in levels of anti-malarial IgG2 between the AS and AA genotype carriers.

\section{Conclusion}

In conclusion, the relative resistance to malaria seen in the Fulani as compared to the Dogon appears not to be a generally more reactive immune system, but rather a pathogen related phenomenon. Furthermore, the results indicate that the FcrRIIa $131 \mathrm{H}$ allele may be associated with a lower susceptibility to malaria in the Fulani group as compared to other sympatric ethnic groups, and also that the Fc $\gamma$ RIIa R131H polymorphism may have an influence on the IgG subclass responses and thereby affecting the malaria susceptibility.

\section{Competing interests}

The authors declare that they have no competing interests.

\section{Authors' contributions}

EI contributed to the design of the study, performed the Fc $\gamma$ RIIa genotyping and the ELISA, carried out the statistical analyses and drafted the manuscript. MV carried out the parasite genotyping. BM examined all study subjects in Mali and collected all clinical data. AL contributed to the FcrRIIa genotyping and the ELISA. NI performed the sickle cell analyses. $\mathrm{AD}$ and $\mathrm{OKD}$ were responsible for clinical data in Mali. KB designed the study. MTB and KB revised the manuscript and financed and supervised the research. All authors read and approved the final manuscript.

\section{Acknowledgements}

We express our appreciation to the blood donors whose participations have made this study possible. This work was supported by grants to MTB and KB from the Swedish Agency for Research Development with Developing Countries (SIDA, SAREC), the Swedish Medical Research Council (VR), as well as by grants within the BioMalPar European Network of Excellence (LSMP-CT-2004-503578).

\section{References}

I. Aribot G, Rogier C, Sarthou JL, Trape JF, Balde AT, Druilhe P, Roussilhon C: Pattern of immunoglobulin isotype response to Plasmodium falciparum blood-stage antigens in individuals living in a holoendemic area of Senegal (Dielmo, west Africa). Am J Trop Med Hyg 1996, 54:449-457.

2. Taylor RR, Allen SJ, Greenwood BM, Riley EM: IgG3 antibodies to Plasmodium falciparum merozoite surface protein 2 (MSP2): increasing prevalence with age and association with clinical immunity to malaria. Am J Trop Med Hyg 1998, 58:406-4I3.

3. Aucan C, Traore $Y$, Tall F, Nacro B, Traore-Leroux T, Fumoux F, Rihet P: High immunoglobulin G2 (IgG2) and low IgG4 levels are associated with human resistance to Plasmodium falciparum malaria. Infect Immun 2000, 68: I 252-I 258.

4. Ntoumi F, Flori L, Mayengue PI, Matondo Maya DW, Issifou S, Deloron P, Lell B, Kremsner PG, Rihet P: Influence of carriage of hemoglobin AS and the Fc $\gamma$ receptor Ila-RI 3 I allele on levels of immunoglobulin G2 antibodies to Plasmodium falciparum merozoite antigens in Gabonese children. J Infect Dis 2005, 192:1975-1980.

5. Pol W van der, Winkel JG van de: IgG receptor polymorphisms: risk factors for disease. Immunogenetics 1998, 48:222-232.

6. Warmerdam PA, Winkel JG van de, Vlug A, Westerdaal NA, Capel PJ: A single amino acid in the second Ig-like domain of the human Fcy receptor II is critical for human IgG2 binding. J Immunol 1991, 147:1338-1343.

7. Parren PW, Warmerdam PA, Boeije LC, Arts J, Westerdaal NA, Vlug A, Capel PJ, Aarden LA, Winkel JG van de: On the interaction of IgG subclasses with the low affinity Fcy RIla (CD32) on human monocytes, neutrophils, and platelets. Analysis of a functional polymorphism to human IgG2. J Clin Invest 1992, 90:1537-1546.

8. Braga ÉM, Scopel KKG, Komatsu NT, da Silva-Nunes M, Ferreira MU: Polymorphism in the Fc $\gamma$ receptor IIA and malaria morbidity. I Mol Gen Med 2005, I:5-10.

9. Nasr A, Iriemenam NC, Troye-Blomberg M, Giha HA, Balogun HA, Osman OF, Montgomery SM, EIGhazali G, Berzins K: Fc $\gamma$ receptor Ila (CD32) polymorphism and antibody responses to asexual blood-stage antigens of Plasmodium falciparum malaria in Sudanese patients. Scand J Immunol 2007, 66:87-96.

10. Sinha S, Mishra SK, Sharma S, Patibandla PK, Mallick PK, Sharma SK, Mohanty S, Pati SS, Mishra SK, Ramteke BK, Bhatt RM, Joshi H, Dash AP, Ahuja RC, Awasthi S, Consortium IG, Venkatesh V, Habib S: Polymorphisms of TNF-enhancer and gene for Fc $\gamma$ RIla correlate with the severity of falciparum malaria in the ethnically diverse Indian population. Malar J 2008, 7:13.

II. Greenwood BM, Groenendaal F, Bradley AK, Greenwood AM, Shenton $F$, Tulloch S, Hayes R: Ethnic differences in the prevalence 
of splenomegaly and malaria in The Gambia. Ann Trop Med Parasitol 1987, 81:345-354.

12. Modiano D, V P, Sirima BS, Nebie I, Diallo D, Esposito F, Coluzzi M: Different response to Plasmodium falciparum malaria in west African sympatric ethnic groups. Proc Natl Acad Sci USA 1996, 93:|3206-|32||.

13. Dolo A, Modiano D, Maiga B, Daou M, Dolo G, Guindo H, Ba M, Maiga H, Coulibaly D, Perlman H, Blomberg MT, Toure YT, Coluzzi $M$, Doumbo O: Difference in susceptibility to malaria between two sympatric ethnic groups in Mali. Am J Trop Med Hyg 2005, 72:243-248.

14. Bolad A, Farouk SE, Israelsson E, Dolo A, Doumbo OK, Nebie I, Maiga B, Kouriba B, Luoni G, Sirima BS, Modiano D, Berzins K, TroyeBlomberg M: Distinct interethnic differences in immunoglobulin $G$ class/subclass and immunoglobulin $M$ antibody responses to malaria antigens but not in immunoglobulin $G$ responses to nonmalarial antigens in sympatric tribes living in West Africa. Scand I Immunol 2005, 61:380-386.

15. Modiano D, Luoni G, Sirima BS, Lanfrancotti A, V P, Cruciani F, Simpore J, Ciminelli BM, Foglietta E, Grisanti P, Bianco I, Modiano G, Coluzzi M: The lower susceptibility to Plasmodium falciparum malaria of Fulani of Burkina Faso (west Africa) is associated with low frequencies of classic malaria-resistance genes. Trans R Soc Trop Med Hyg 200I, 95: I49-I52.

16. Jensen JB, Trager W: Plasmodium falciparum in culture: establishment of additional strains. Am J Trop Med Hyg 1978, 27:743-746.

17. Lambros C, Vanderberg JP: Synchronization of Plasmodium falciparum erythrocytic stages in culture. J Parasitol 1979, 65:418-420.

18. Troye-Blomberg M, Romero P, Patarroyo ME, Bjorkman A, Perlmann $P$ : Regulation of the immune response in Plasmodium falciparum malaria. III. Proliferative response to antigen in vitro and subset composition of $\mathrm{T}$ cells from patients with acute infection or from immune donors. Clin Exp Immunol 1984, 58:380-7.

19. Jiang XM, Arepally G, Poncz M, McKenzie SE: Rapid detection of the Fc $\gamma$ RIIA-H/R I I ligand-binding polymorphism using an allele-specific restriction enzyme digestion (ASRED). J Immunol Methods 1996, 199:55-59.

20. Snounou G, Zhu X, Siripoon N, Jarra W, Thaithong S, Brown KN, Viriyakosol S: Biased distribution of $\mathbf{m s p l}$ and $\mathbf{m s p 2}$ allelic variants in Plasmodium falciparum populations in Thailand. Trans $R$ Soc Trop Med Hyg 1999, 93:369-374.

21. Nasr A, Elghazali G, Giha H, Troye-Blomberg M, Berzins K: Interethnic differences in carriage of haemoglobin AS and Fc $\gamma$ receptor Ila (CD32) genotypes in children living in eastern Sudan. Acta Trop 2008, 105:191-195.

22. Ouma C, Keller CC, Opondo DA, Were T, Otieno RO, Otieno MF, Orago AS, Ong'echa JM, Vulule JM, Ferrell RE, Perkins DJ: Association of Fcy receptor Ila (CD32) polymorphism with malarial anemia and high-density parasitemia in infants and young children. Am J Trop Med Hyg 2006, 74:573-577.

23. Cooke GS, Aucan C, Walley AJ, Segal S, Greenwood BM, Kwiatkowski DP, Hill AV: Association of Fc $\gamma$ receptor Ila (CD32) polymorphism with severe malaria in West Africa. Am J Trop Med Hyg 2003, 69:565-568.

24. Osborne JM, Chacko GW, Brandt JT, Anderson CL: Ethnic variation in frequency of an allelic polymorphism of human $\mathrm{Fc} \gamma$ RIIA determined with allele specific oligonucleotide probes. J Immunol Methods 1994, 173:207-217.

25. Reilly AF, Norris CF, Surrey S, Bruchak FJ, Rappaport EF, Schwartz E, McKenzie SE: Genetic diversity in human Fc receptor II for immunoglobulin G: Fcy receptor IIA ligand-binding polymorphism. Clin Diagn Lab Immunol 1994, I:640-644.

26. Modiano D, Luoni G, Petrarca V, Sodiomon Sirima B, De Luca M, Simpore J, Coluzzi M, Bodmer JG, Modiano G: HLA class I in three West African ethnic groups: genetic distances from subSaharan and Caucasoid populations. Tissue Antigens 200I, 57:128-137.

27. Omi K, Ohashi J, Patarapotikul J, Hananantachai H, Naka I, Looareesuwan S, Tokunaga $\mathrm{K}$ : Fc $\gamma$ receptor IIA and IIIB polymorphisms are associated with susceptibility to cerebral malaria. Parasitol Int 2002, 5 I:36I-366.

28. Brouwer KC, Lal AA, Mirel LB, Otieno J, Ayisi J, Van Eijk AM, Lal RB, Steketee R, Nahlen BL, Shi YP: Polymorphism of Fc receptor Ila for immunoglobulin $\mathbf{G}$ is associated with placental malaria in HIV-I-positive women in western Kenya. J Infect Dis 2004, 190:I192-II98.

29. Shi YP, Nahlen BL, Kariuki S, Urdahl KB, McElroy PD, Roberts JM, Lal $A A:$ Fc receptor Ila (CD32) polymorphism is associated with protection of infants against high-density Plasmodium falciparum infection. VII. Asembo Bay Cohort Project. J Infect Dis 200I, I84:107-III.

30. Bereczky S, Liljander A, Rooth I, Faraja L, Granath F, Montgomery SM, Färnert A: Multiclonal asymptomatic Plasmodium falciparum infections predict a reduced risk of malaria disease in a Tanzanian population. Microbes Infect 2007, 9:103-II0.

31. Färnert A: Plasmodium falciparum population dynamics: only snapshots in time? Trends Parasitol 2008, 24:340-344.

32. Groux H, Gysin J: Opsonization as an effector mechanism in human protection against asexual blood stages of Plasmodium falciparum: functional role of IgG subclasses. Res Immunol 1990, | $41: 529-542$.
Publish with Bio Med Central and every scientist can read your work free of charge

"BioMed Central will be the most significant development for disseminating the results of biomedical research in our lifetime. "

Sir Paul Nurse, Cancer Research UK

Your research papers will be:

- available free of charge to the entire biomedical community

- peer reviewed and published immediately upon acceptance

- cited in PubMed and archived on PubMed Central

- yours - you keep the copyright

Submit your manuscript here:

http://www.biomedcentral.com/info/publishing_adv.asp 